\title{
PRIMARY SCHOOL STUDENTS' READING LEVELS OF LINE GRAPHS
}

\author{
PEDRO ARTEAGA \\ University of Granada, Spain \\ parteaga@ugr.es \\ DANILO DÍAZ-LEVICOY \\ Catholic University of Maule, Chile \\ dddiaz01@hotmail.com \\ CARMEN BATANERO \\ University of Granada, Spain \\ batanero@ugr.es
}

\begin{abstract}
The aim of this research was to describe the errors conveyed and reading levels reached by $6^{\text {th }}$ and $7^{\text {th }}$ grade Chilean primary school children when working with line graphs. To achieve these objectives, we gave a questionnaire, previously validated by experts with two open-ended tasks, to a sample of 745 students from different Chilean cities. In the first task, we asked the children to read the title of the graph, describe the variables represented and perform a direct and inverse reading of a data value. In the second task, where we address the visual effect of a scale change in a representation, the students had to select the line graph most favourable for a candidate. Although both tasks were considered easy for the grade levels targeted, only some of the students achieved the highest reading level and many made occasional errors in the reading of the graphs.
\end{abstract}

Keywords: Statistics education research; Line graphs; Reading levels; Primary school children

\section{INTRODUCTION}

Nowadays, the competence of reading elementary statistical graphs is considered part of statistical literacy, needed to function in society, due to the abundance of data representations presented in the media (Engel, 2019; Ridgway, 2016). In addition, graphs appear in textbooks of different subjects (mathematics, natural and social sciences, etc.), as well as in educational software, with the aim of helping students understand scientific or social data (Shah \& Hoeffner, 2002).

Due to this relevance, statistical graphs and, in general, statistics has been introduced in primary school in many countries. For example, line graphs are taught in primary school in other countries, such as Spain (MECD, 2014) and Costa Rica (MEP, 2012), and are recommended in the Common Core State Standards for Mathematics (CCSSI, 2010). The Chilean curricular guidelines (MINEDUC, 2012) suggest explicitly in the learning chapter about data and probability that students work with the following graphs: pictograms (first to fourth grades), bar graphs (second to fifth grades), point charts (third and sixth grades), line graphs (fifth grade), stem and leaf diagrams (fifth and sixth grades), and compound bar graphs and pie chart (sixth grade). Furthermore, our previous study of Chilean mathematics textbooks served to verify that all these graphs are used at the levels mentioned in the curricular guidelines (Díaz-Levicoy et al., 2016).

Even though research focusing on children's ability to read and build statistical graphs and exploration of the level of complexity of the graphical tasks that can be proposed to the children has increased recently, there is no previous research on the reading of line graphs by Chilean children. Consequently, the aim of this research was to describe the errors conveyed and reading levels reached by $6^{\text {th }}$ and $7^{\text {th }}$ grade Chilean primary school children reach when working with line graphs. This information will help teachers improve their teaching of the topic. 


\section{BACKGROUND}

We firstly focus on the graph reading levels described by Curcio and his collaborators (Curcio, 1989; Friel et al., 2001; Shaughnessy et al., 1996), and secondly on previous research that analysed the reading of graphs by primary school children.

\subsection{READING LEVELS OF GRAPHS}

Using the same statistical graph, we can pose questions of different levels of difficulty, which can refer to the title and scales, the variables and values being represented, the interpolation or extrapolation of values, and the detection of biases in the graph or in statements based on the graph. The responses to these questions require a series of interpretative processes of each component of the graph and of the graph as a whole, as well as of the relationship of the graph with the context of the data (Arteaga et al., 2012; Tufte, 2001).

This interpretation is more or less complex, depending on the information that needs to be extracted from the graph, and for this reason, several authors have defined levels in the reading of graphs. In this research, we relied on those defined by Curcio and his collaborators (Curcio, 1989; Friel et al., 2001; Shaughnessy et al., 1996):

R1. Reading the data, where only the literal reading of a graph element is requested, for example, reading the graph title, the scale labels, or the frequency for a given value.

R2. Reading between the data. Besides the literal reading of the graph, at this level children compare various data represented in the graph or complete some arithmetical calculations with the data.

R3. Reading beyond the data. This level involves a generalization of the values in the graph, for example, interpolating or extrapolating the information displayed.

R4. Reading behind the data. Children attain this level when they make a critical evaluation of the graph, of the way it was constructed or discuss a statement related to the graph content.

\subsection{CHILDREN'S GRAPHICAL COMPETENCE AND READING LEVELS}

Below we summarise research on children's graphical understanding that is relevant in our work.

Guimarães (2002) studied the interpretation of bar graphs by $1073^{\text {rd }}$ grade primary school children in Brazil and reported that $72 \%$ of the children achieved specific reading (finding the maximum, minimums and locating frequencies or categories) and 54.2\% of them were able to perform an extrapolation from data not represented in the graph, even though it is more difficult to read non-explicit frequency. However, when asked to locate the part of the graph with the greatest increase or decrease, they only obtained $26.3 \%$ correct answers.

In another study, Pagan et al. (2008) analysed the reading of tables and graphs by $3995^{\text {th }}$ and $8^{\text {th }}$ grade students in Brazil, including simple and compound bar graphs. They reported that $84 \%$ of the students correctly performed the tasks involving the reading level R1, with $43 \%$ those of reading level R2.

Canché (2009) adminstered a multiple-choice questionnaire with statistical graphs (two pictograms, two pie charts, two line graphs and a bar graph) to $2066^{\text {th }}$ grade students in Mexico. His results showed $69.1 \%$ of correct answers in tasks requesting level R1, 50.6\% in the R2 level questions, and $51 \%$ in the level R3 tasks. Concerning pictograms, $62.6 \%$ of the children reached level R1, $45.6 \%$ of them R2 and $51 \%$ R3. In line graphs, $41 \%$ of the children succeeded at R1 level, $43 \%$ at R2 and $26.7 \%$ at R3. Referring to pie charts $90.6 \%$ performed correctly at level R1, $57.1 \%$ at R2, and $63.4 \%$ at R3. Finally, the percentages of students succeeding in activities related to bar graphs were $95.1 \%$ in R1, $62.6 \%$ in $\mathrm{R} 2$ and $50.5 \%$ in $\mathrm{R} 3$.

Fernándes and Morais (2011) analysed the responses by $1089^{\text {th }}$ grade students to activities related to the reading of a bar graph, a pie chart and a line graph. They obtained 68\% correct responses to level R1 questions, $33 \%$ to R2 and $24 \%$ to R3. In the bar graph $90 \%$ of students attained the level R1 and $23 \%$ the level R2. In the pie chart, $96 \%$ of the sample succeeded at the level R1, 31\% at R2 and $23 \%$ at R3. In the line graph 19\% of children the level R1, 14\% the level R2 and 43\% the level R3. 
Cruz (2013) analysed the reading of statistical graphs by $223^{\text {rd }}$ grade students in Lisbon, within a teaching experiment. She applied a pre-test and a post test, which included two activities related to reading graphs (a pictogram and a pie chart). Students achieved better results when working with the pictogram (70\%) than with the pie chart (21.3\%). Regarding the reading levels, regardless of the type of graph, $53.8 \%$ of the students replied correctly to the R1 activities, $46.8 \%$ to the R2 and $24.5 \%$ to the R3 tasks.

Cavalcanti (2010) studied the understanding of the concept of scale in statistical graphs by 152 primary school students (Groups: $371^{\text {st }}$ grade, $373^{\text {rd }}$ grade, $313^{\text {rd }}$ grade, $\& 475^{\text {th }}$ grade children) and young adult students. The results of that research suggest poor results regardless of the educational level. In general, primary school students, mainly in $5^{\text {th }}$ grade had better results than young adult students. This author presents an activity with two graphs with the same information and different scales, and the students were to indicate which graph a candidate would choose in his choice campaign. Forty percent of the students adequately indicated the graph to choose, but their justifications ranged from being limited to incorrect reasons (e.g., that a graph included more data because the scale on the Y axis reached up to $100 \%$ ) or did not consider the graph in the response (e.g., that one candidate was more friendly than the other).

Evangelista (2013) analysed the performance of $605^{\text {th }}$ grade primary school students in Brazil, when working with bar and line graphs and put forward eight graph interpretation activities with reading level R1 and R2 to the children. The students correctly answered 51\% of these activities, and the best results were achieved in the bar graphs, while the worst performance corresponded to the double line graphs. On average, 59\% of the students answered correctly the activities related to bar graphs and $43 \%$ of those corresponding to line graphs. The activities of locating frequencies or categories had $60 \%$ achievement, the computation of the mode $51 \%$ and the sum of values $41 \%$. Later, Evangelista (2014) described a classroom intervention to work the concept of scale in bar and line graphs with $695^{\text {th }}$ grade primary school students in Brazil, which was evaluated through the application of a pre and a post-test. In these tests, three of the eight questions were focused on the line graph. In the first question, the student had to build the scale ( $Y$ axis), and the students rose from $15 \%$ to $45 \%$ success after the intervention. In the second activity, the children had to locate some implicit values according to what was observed in the scale, and the percentages of achievement rose from 13\% to 29\%. And, in the third activity, adapted from Cavalcanti (2010), the students had to choose the most appropriate graph for a situation, from two graphs presenting the same information and different scale; only one student responded correctly in the pre-test and four in the post-test.

Fernandes et al. (2017) described a work focused teaching sequence of statistical tables and graphs with $355^{\text {th }}$ grade primary school students in Brazil. They analysed the learning by comparing the results of a pre-test and a post-test. They reported that $63.3 \%$ of participants correctly answered the question about a pictogram in the pre-test and $100 \%$ in the post-test, $86.7 \%$ of them correctly interpreted a bar graph in the pre-test and $100 \%$ in the post-test for the R1 level question and $77.1 \%$ in the pre-test, while $97.2 \%$ succeeded in the post -test for the R2 level question.

In Batanero et al. (2018), we reported the reading levels of pictograms for the same sample of Chilean children that is part of the work described in this paper. The children were given two activities, in one of which they could reach level R2 and in another the level R4. In the first task, consisting of translating the information represented in a pictogram to a table, $1.9 \%$ did not attain level R1, 98.1\% achieved the R1 and $92.6 \%$ the R2. In the second activity, where children could discuss two statements based on the graph, only $6 \%$ of the children reached the level R4 in the first question and $13 \%$ of them in the second question, although practically the entire sample $(98.4 \%$ and $97.7 \%)$ reached the level R1, and the majority $(61 \%$ and $64.3 \%)$ the level R2. Level R3 was not taken into account.

The research referred to in this section focused on the graphs that usually include the curricular guidelines of the countries where they were carried out, but we did not find studies with Chilean children on the reading of the line graph.

\section{METHOD}

Overall, 745 Chilean primary school children, who attended 13 schools in seven different cities, took part in the research, 380 of them in $6^{\text {th }}$ grade (11-12 years) and 365 in $7^{\text {th }}$ grade (12-13 years). The average age of the children was 12.3 years, and the percentage of girls in the sample was $50.9 \%$. The 
children studied the statistical content included in the Chilean curricular guidelines (MINEDUC, 2012) in the previous years, including pictograms (first to fourth grades), bar graphs (second to fifth grades), point charts (third grade), line charts (fifth grade), and stem and leaf diagrams (fifth grade). The access to the classrooms was facilitated by the prior authorization of the centres' directors and of the teachers responsible for the groups, who collaborated with the second author, who travelled to Chile to collect the data. The task was completed within a mathematics lesson and the purpose of the study was explained to the children.

The children collaborated with interest, and, in a later session, the tasks were corrected collaboratively, so that the activity had an educational interest and benefit for the children. In the examples shown in this article, we assign a code $(\mathrm{Sn})$ to each student, where $n$ is the order number of the child in the data table.

\subsection{TASKS PROPOSED TO THE CHILDREN}

The first task (Figure 1) was adapted from a Chilean primary school $5^{\text {th }}$ degree textbook (Ávila et al., 2013). To answer the questions posed, each student had to recognize the elements of the graph, identify the title (question 1) and the variables represented (question 2), read a value from the graph (question 3) and the category associated with a given value (inverse reading) (last question). All these responses were included in level $R 1$ reading the data from Curcio et al. (Curcio, 1989; Friel et al., 2001).

Look at the following line graph and then answer the questions that follow:

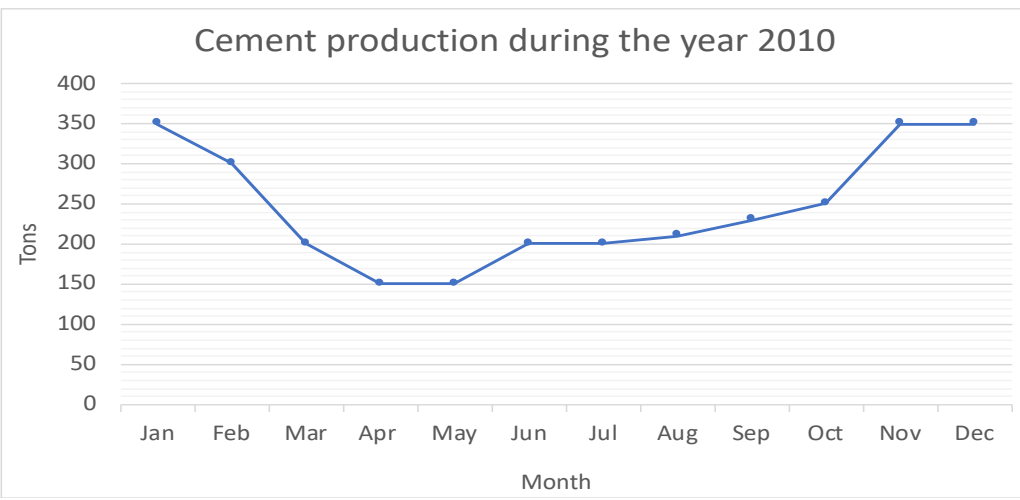

1. What is the title of the graph?

2. Which variables are represented?

3. How many tons of cement were produced during the month of February?

4. In which month (s) was the production 200 tons of cement?

Figure 1. First task

The second task (Figure 2) was adapted from another question used in previous research (Cavalcanti, 2010; Evangelista, 2014). The students were asked to choose between two-line graphs (which represent two short series of data) the one that showed the most benefit for a candidate (Pedro), and to justify their choice. The two graphs present the same information but differed in the scale used. To correctly solve the task, an R4 level is required, reading behind the data (Friel et al., 2001; Shaughnessy et al., 1996), because a critical analysis of the graph should be performed, and the students have to understand the visual effect produced when modifying the scale. The second graph favours the candidate Pedro because the small difference ( 2 points in August) is visually exaggerated, as it is the growth between April and August, when compared to that of Gabriel. We should also remember that, as Shah and Hoeffner (2002) point out, it is easier to identify trends in a two-dimensional line graph, such as those used in our task, than in other types of graph, for example, a bar diagram representing the same information. 


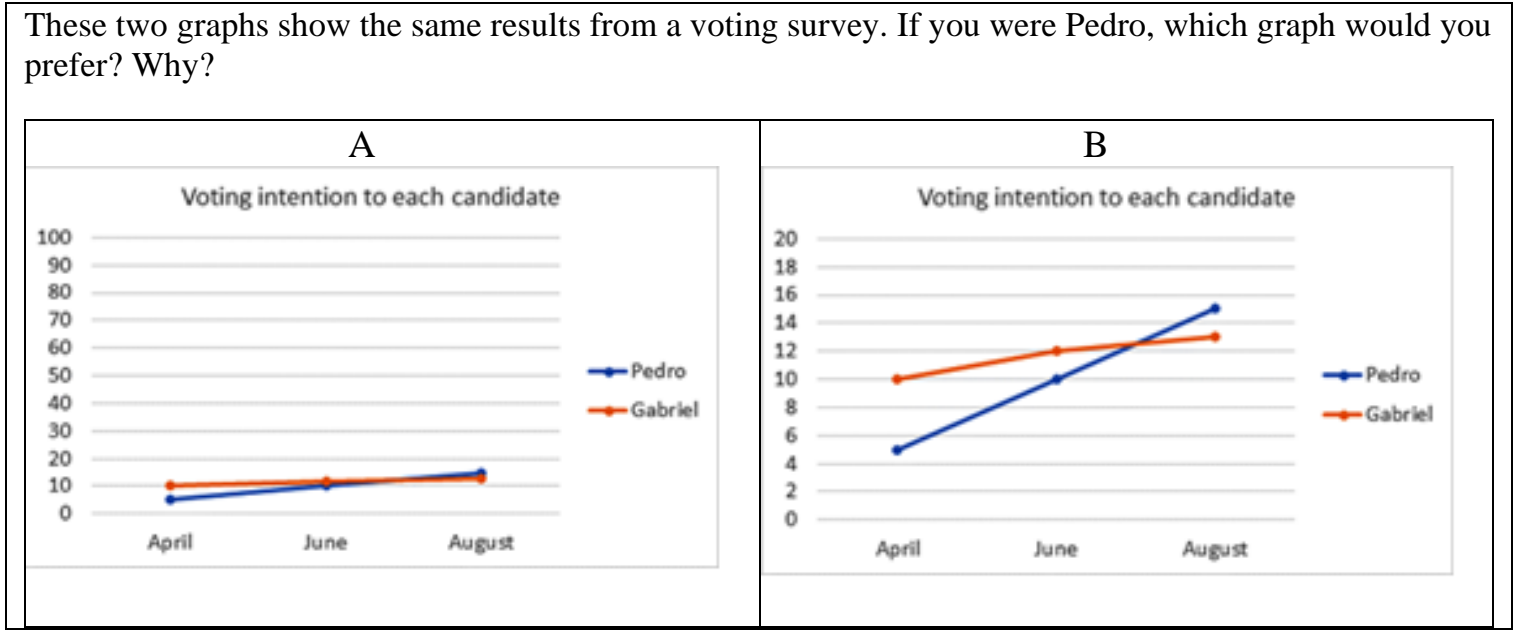

Figure 2. Second task

\section{RESULTS}

\subsection{RESULTS FOR THE FIRST TASK}

First question: Reading the graph title. The first question in Task 1 asked to identify the title of the graph, that is, the production of cement during 2010. It is a simple activity, which allowed the students to demonstrate understanding of the context of the information represented. The answer was considered correct if the student gave the exact title, as in the case of S184, or omitsled a word, but maintained the central idea of the title:

S184: Cement production during 2010.

The response was considered incorrect if it was not related to the graph title. This type of response, although very scarce, was given by S119, who replied with the name of a type of graph different from the line graph:

S119: Dot plot.

In Table 1 we present the results of the reading of the graph title, where $95 \%$ of grade 6 students identified the title correctly. In comparing the results by grade, we observed a slightly higher percentage of success in $6^{\text {th }}$ grade students, although the percentage is high in both groups. We found this confirmed previous research about children's competence to read the graph title.

Table.1. Distribution of responses according correctness in the reading of the title

\begin{tabular}{lccc}
\hline Reading of the title & $6^{\text {th }}$ Grade $(n=380)$ & $7^{\text {th }}$ Grade $(n=365)$ & Total $(n=745)$ \\
\hline Correct & 95 & 93.7 & 94.4 \\
Incorrect & 1.1 & 2.5 & 1.7 \\
No answer & 3.9 & 3.8 & 3.9 \\
\hline
\end{tabular}

Second question: Identifying the variables. In this part the response was correct when the student clearly identified the two variables represented and described the variables, sometimes using an imprecise language, due to his or her age. An example is the response given by S21:

S21: How many tons are produced each month?

The response was partly correct if the student described only one variable and omitted the other variable, such as, for example:

S8: Tons. 
The response was incorrect if the student was unable to describe clearly the variables represented in the graph. We found the following categories of incorrect responses:

- I1. Listing the labels for the scale corresponding to one variable. Instead of describing the variable, the labels on one of the axes are listed. For example, S6 listed the labels on the $Y$ axis. These students confused the concepts of value and variable.

S6: $\quad 350,300,250,200,150,100,50,0$.

- I2. Computing the range or finding the extremes: Instead of describing the variables, the student reported the range of variation of one or both variables, reproduced one or both of the maximum and the minimum or the months in which these values were reached. For example, S113 provided the smallest of the data represented in the graph. In this response the student was able to read the graph at level R2 (Curcio, 1987), reading between the data, since he performed calculations with the data.

S113: 150 .

- I3. Describing the data trend. The child describes the trend followed by the values represented in the graph over the period of time considered. For example, S33 points to the trend changes in the values for specific months. This student also reached Curcio's (1987) level R2, even when his answer, regarding the graph title was incorrect.

S33: It starts smoothly, then in April descends little by little and again rises.

- I4. Listing the data. The child replied with the values of production in each month, so that he had to read these data:

S104: $\quad 350,300,200,150,150,200,200,230,240,250,350,350$.

- I5. Counting the different values in one scale. For example, S44 suggested there were seven different values (corresponding to the cement production in the year).

S44: $\quad$ There are 7 variables.

- I6. Reporting the months close to the maximum. When the child reported the months before and after the maximum.

S10: $\quad$ February and October.

In Table 2 we present the percentages of the type of responses to this task, where a high proportion (around 40\%) of students did not respond, which suggests they had difficulties with the concept of variables. Students who could successfully identify the two variables represented did not reach $20 \%$, and $6^{\text {th }}$ grade students obtained a slightly higher success rate than those in $7^{\text {th }}$ grade.

Table 2. Distribution of responses according to correctness in describing the variables

\begin{tabular}{lccc}
\hline Describing the variables & $6^{\text {th }}$ Grade $(n=380)$ & $7^{\text {th }}$ Grade $(n=365)$ & Total $(n=745)$ \\
\hline Correct & 20.3 & 16.4 & 18.4 \\
Partly correct & 17.9 & 22.7 & 20.3 \\
Incorrect & 24.2 & 21.4 & 22.8 \\
No answer & 37.6 & 39.5 & 38.5 \\
\hline
\end{tabular}

In Table 3 we present the frequency of the different errors found in the incorrect answers. All of these errors appeared in a small proportion of students; the most frequent mistakes were listing the labels for a scale, computing the range of the variable, or else the maximum or minimum values in the graph. We did not find previous research describing the students' competence in identifying the variables in a graph. 
Table 3. Percentage of errors in the incorrect responses

\begin{tabular}{lccc}
\hline \multicolumn{1}{c}{ Type of error } & $6^{\text {th }}$ Grade $(n=380)$ & $7^{\text {th }}$ Grade $(n=365)$ & Total $(n=745)$ \\
\hline I1. Listing the labels for the scale & 7.4 & 6.6 & 7 \\
I2. Computing the range or finding the extremes & 6.6 & 4.4 & 5.5 \\
I3. Describing the data trend & 0.3 & 1.4 & 0.8 \\
I4. Listing the data & 1.6 & 0.3 & 0.9 \\
I5. Counting the different values in one scale & 0.5 & 0.3 & 0.4 \\
I6. Reporting months close to the maximum & 0.3 & 0 & 0.1 \\
I7. Other & 7.6 & 8.5 & 8.1 \\
\hline
\end{tabular}

Third question: reading data. Thirdly, we asked the children to perform a direct reading of data from the graph; specifically, they were asked to find the amount of cement produced in February. The students' responses were considered correct when they replied that in the month of February the production was 300 tons of cement (with slight variations, such as the following student):

S138: In February 300 tons of cement were produced.

We can observe in Table 4 that the task was easy for the students, since around $93 \%$ of them correctly performed the direct reading. The results are better than those of Guimarães (2002), who obtained $72 \%$ success in direct reading of graphs by $3^{\text {rd }}$ grade children; these differences are reasonable, due to the older age of the students in our sample.

Table 4. Percentage of students according to direct reading of a data

\begin{tabular}{lccc}
\hline Type of response & $6^{\text {th }}$ Grade $(n=380)$ & $7^{\text {th }}$ Grade $(n=365)$ & Total $(n=745)$ \\
\hline Correct & 93.4 & 93.2 & 93.3 \\
Incorrect & 1.8 & 3 & 2.4 \\
No answer & 4.7 & 3.8 & 4.3 \\
\hline
\end{tabular}

Fourth question: Inverse reading of the graph. In the last activity of this item, we asked the students to carry out an inverse reading, that is, given a graph value, we asked them to determine its associated category. The students' answers were considered correct if they were able to identify the three months in which the cement production was 200 tons: March, June, and July. For example:

S169: In March, June, July.

The response was considered partly correct when a student pointed to at least one month with 200 tons of production or else he or she read some months correctly and failed in reading other months:

S138: In March August and June.

The response was incorrect when a student failed to perform the inverse reading of the graph and could not find the month with 200 tons of production, such as for example:

S85: January, February, November and December.

Table 5. Percentage of responses in the inverse reading of the graph

\begin{tabular}{lccc}
\hline Type of response & $6^{\text {th }}$ Grade $(n=380)$ & $7^{\text {th }}$ Grade $(n=365)$ & Total $(n=745)$ \\
\hline Correct & 62.9 & 62.2 & 62.6 \\
Partly correct & 30 & 32.9 & 31.4 \\
Incorrect & 0.8 & 1.4 & 1.1 \\
No answer & 6.3 & 3.6 & 5 \\
\hline
\end{tabular}

In Table 5 we present the distribution of the students' responses for this question, where most of them correctly performed an inverse reading. In general, about $95 \%$ of children identified at least one 
of the months in which 200 tons of cement were produced. When comparing the results by grade, we saw that more $6^{\text {th }}$ grade students successfully read the three months, with a small difference; although, in total, more $7^{\text {th }}$ grade students successfully found at least one month. Although we did not find previous work to compare the children' inverse reading of graph, our results are better than those reported by Evangelista (2014) in the explicit and implicit reading of the scale in a graph, which may be explained because in our task the children did not need to estimate the values.

\subsection{RESULTS FOR THE SECOND TASK}

Selecting the graph. In this task we requested students explain which graph one of the candidates (Pedro) would select in his electoral campaign between two graphs displaying the same information, with different scales. To perform the task, the child should interpret the title of the graph, in order to understand the context and the information represented. In the same mode he or she should read the labels of categories (intention vote in three months for two candidates). It is necessary to understand that lines of different colours serve to differentiate the data for the two candidates. Once the child performs all these interpretations, he or she has to compare the scales of the two graphs and observe that the first scale is too wide for the data presented and does not show in detail the differences between the candidates. In the second scale the slopes of each graph are exaggerated, especially those corresponding to Pedro. Therefore, students are expected to choose the second graph, with a lower rank in the scale, in which Pedro's slight advantage over the other candidate (Gabriel) is exaggerated. While this type of activity can be difficult for primary school students, we were interested to know if they could perceive the effect of a change of scale, which is frequently found in everyday life.

In Table 6 we present the percentages of the graphs selected by the students. In general, over $60 \%$ of the students chose the correct graph, which is a very good result, Considering the difficulty of this task, in which the $6^{\text {th }}$ grade students obtained slightly better results than the 7 th grade students $(64.5 \%$ versus $60.5 \%$ ). These results are higher than those achieved in Evangelista (2013), where only $4.3 \%$ of her students responded correctly in the pre-test and $17.4 \%$ in the post-test. Our results are also better than those by Cavalcanti (2010) in an investigation with elementary and adult education students, where they reached a $40 \%$ success rate. We also point to the high percentage of students who did not respond to this task.

Table 6. Percentage of students selecting each graph

\begin{tabular}{llll}
\hline Selected graph & $6^{\text {th }}$ Grade $(n=380)$ & $7^{\text {th }}$ Grade $(n=365)$ & Total $(n=745)$ \\
\hline A & 9.7 & 12.1 & 10.9 \\
B & 64.5 & 60.5 & 62.6 \\
Both (A and B) & 0.3 & 0.5 & 0.4 \\
No answer & 25.5 & 26.8 & 26.2 \\
\hline
\end{tabular}

Reading level. We analysed the reading levels that students reached when justifying the graph that the candidate (Pedro) should select. We categorized the answers by using the levels defined by Curcio et al. (Curcio, 1989; Friel et al., 2001; Shaughnessy et al., 1996), according to the following criteria:

- $R 0$. We assigned this level when a student did not reply to the question, or the answer was inconsistent. In addition, the student did not read any value from the graph:

S315: Graph A because I think it's better done.

- R1. Reading the data. The child performed the direct reading of a data point or a few data, but did not produce computations or interpretation of the data.

S441: $\quad$ Because in graph A there is 1 and in graph B there is 4 .

- R2. Reading between the data. In addition to literally reading the information provided in the graph, the child performed some computation or discovered some relationships in the data. An example was pointing to the tendency of a candidate with no specification of a specific graph.

S17: Because Pedro is increasing. 
- R3. Reading beyond the data. This level involved a generalization of the values in the graph, for example, predicting data not represented in the graph. This level cannot be applied to this task.

- R4. Reading behind the data. This level involves the critical assessment of some features of the graph (type of graph, information obtained, data collection, conclusion, etc.). For this particular task, the student should select the correct graph and understand that both graphs display the same information, with different scales. This difference provokes a visual effect that can be used by one candidate. We assigned level R4 to those children who used this reasoning, even with some imprecisions in their argument:

ES25: Because when comparing the graphs, I noticed that in graph A both (candidate) look quite identical, but in B, all change, since in diminishing the amount of numbers (that is, in pairs) Pedro seems to be winning and this is why he selected $\mathrm{B}$.

In Table 7, we present the distribution of the reading levels reached by the students in their responses to this task. Globally, most of the students were situated at the $\mathrm{R} 2$ level (reading between the data), that is, their answers are based on comparing the values, and perceiving the differences between the percentages of voting intentions. Therefore, these students succeeded in reading the graphs correctly and observed the differences, but did not reach the critical reading capacity, except for a small percentage. Blank or incoherent responses were relatively frequent.

Table 7. Distribution of children's reading levels in the second task

\begin{tabular}{cccc}
\hline Reading level & $6^{\text {th }}$ Grade $(n=380)$ & $7^{\text {th }}$ Grade $(n=365)$ & Total $(n=745)$ \\
\hline R0 & 29.2 & 31.8 & 30.5 \\
R1 & 5.8 & 4.4 & 5.1 \\
R2 & 53.4 & 47.9 & 50.7 \\
R4 & 11.6 & 15.9 & 13.7 \\
\hline
\end{tabular}

When comparing the results by grade, we observed that in the R4 level (reading behind the data) the $7^{\text {th }}$ grade children presented higher results than their $6^{\text {th }}$ grade colleagues, and that the latter had a higher percentage of questions in the R2 level (read between the data). The percentage of literal reading level R1 was low in both groups with a percentage around 5\%. When comparing these results with those obtained by Evangelista (2014) our results are much better, since in that study $1.4 \%$ of the sample correctly answered the question in the pre-test and 5.8\% in the post -test. Like what happened in Cavalcanti (2010), where only $40 \%$ of the students selected the correct graph.

\section{DISCUSSION AND DIDACTIC IMPLICATIONS}

The results concerning the correctness of the answer are worse than those obtained in research focused on other types of graphs, both in the first task, where only the level of literal reading was requested and more evident in the second task. Thus, Pagan et al. (2008) obtained 67.3\% of correct answers by $5^{\text {th }}$ grade children of primary school in Brazil in reading bar graphs and Fernandes et al. (2017) $63.3 \%$ on reading line graphs and $86.7 \%$ in bar graphs, before their teaching experience.

When analysing the reading level achieved in the students' responses, we saw that the maximum level R4 required in the second task was only attained by a small part of the sample, a percentage very close to that of students reaching this level in the reading of the pictogram in our previous work (Batanero et al., 2018). Consequently, we deduced that the difficulty in reaching R4 level is not due to the kind of graph, but to the fact that few questions of this level are proposed in the textbooks, as shown in Díaz-Levicoy et al. (2016). We think that, for this reason, the children had little familiarity with these types of tasks that should be considered more frequently in teaching.

The percentages of students who reached at least the R2 level in our tasks $\left(65 \%\right.$ in $6^{\text {th }}$ grade and $63.8 \%$ in $7^{\text {th }}$ grade) were quite high, similar to those obtained in our previous work with pictograms (61\% and 64.3\%), and higher than those obtained with line graphs by Canché (2009) (43\%) and Fernandes and Morais (2011) (43\%). In other research on reading graphs the reading level R2 was reached by $43 \%$ of the students in the bar graphs (Pagan et al. 2008), 45.6\% in the pictograms and 
$57.1 \%$ in pie charts (Canché, 2009), and 46.8\% in Cruz's research (2013) on pictograms and pie charts.

In general, the results on reading level obtained were quite good and indicated positive learning

by Chilean children of line graphs. We need, however, to study the children's performance with activities of reading level R3 and organise activities to reinforce their competence in the critical reading of these graphs, that is, at level R4, which is needed to achieve an adequate statistical literacy.

\section{ACKNOWLEDGEMENT}

Project PID2019-105601GB-I00 (MICIN), Group FQM126 (Junta de Andalucía) and grant CONICYT FICHA 72150306

\section{REFERENCES}

Arteaga, P., Batanero, C., Contreras, J. M., \& Cañadas G. (2012). Understanding statistical graphs: A research survey. BEIO. Boletín de Estadística e Investigación Operativa, 28(3), 261-277.

Ávila, J., Fuenzalida, C., Jiménez, M., \& Ramírez, P. (2013). Matemática $5^{\circ}$ Básico. Tomo II. Santillana.

Batanero, C., Díaz-Levicoy, D., \& Arteaga, P. (2018). Evaluación del nivel de lectura y la traducción de pictogramas por estudiantes chilenos de Educación Básica. Avances de Investigación en Educación Matemática, 14, 49-64.

Canché, L. (2009). La comprensión gráfica de los alumnos del nivel primaria. [Master's dissertation. Universidad Autónoma de Yucatán, México]

Cavalcanti, M. (2010). Como adultos e crianças compreendem a escala representada em gráficos. [Master's dissertation, Universidad Federal de Pernambuco, Brasil]

CCSSI. (2010). Common Core State Standards for Mathematics. NGA Center \& CCSSI.

Cruz, A. (2013). Erros e dificuldades de alunos de $1 .^{\circ}$ ciclo na representação de dados estatísticos. [Master's dissertation, Universidad de Lisboa, Portugal]

Curcio, F. R. (1987). Comprehension of mathematical relationships expressed in graphs. Journal for Research in Mathematics Education 18(5), 382-393.

Curcio, F. R. (1989). Developing graph comprehension. NCTM.

Díaz-Levicoy, D., Batanero, C., Arteaga, P., \& Gea, M. M. (2016). Gráficos estadísticos en libros de texto de Educación Primaria: Un estudio comparativo entre y Chile. BOLEMA. Boletim de Educação Matemática, 30(55), 713-737. https://doi.org/10.1590/1980-4415v30n55a20

Engel, J. (2019). Statistical literacy and society. In J. M. Contreras, M. M. Gea, M. M. López-Martín y E. Molina-Portillo (Eds.), Actas del Tercer Congreso Internacional Virtual de Educación Estadística (pp. 1-17). Grupo de Investigación de Educación Estadística. https://www.ugr.es/ fqm126/civeest/ponencias/engel.pdf

Evangelista, B. (2013). Atividades de interpretação de gráficos de barras e linhas: o que sabem os alunos do $5^{\circ}$ ano? En J.M. Contreras, G.R. Cañadas, M.M. Gea \& P. Arteaga (Eds.), Actas de las Jornadas Virtuales en Didáctica de la Estadística, Probabilidad y Combinatoria (pp. 121-128). Departamento de Didáctica de la Matemática de la Universidad de Granada.

Evangelista, B. (2014). Aprendendo a representar escalas em gráficos: um estudo de intervenção. [Master's dissertation, Universidade Federal de Pernambuco, Brasil]

Fernandes, J. A. \& Morais, P. C. (2011). Leitura e interpretação de gráficos estatísticos por alunos do $9^{\circ}$ ano de escolaridade. Educação Matemática Pesquisa, 13(1), 95-115.

Fernandes, R., Santos, G., \& Pereira, R. (2017). Ensino e aprendizagem de gráficos e tabelas nos anos iniciais de escolarização. UNIÓN. Revista Iberoamericana de Educación Matemática, 50, 41-61.

Friel, S., Curcio, F., \& Bright, G. (2001). Making sense of graphs: Critical factors influencing comprehension and instructional implications. Journal for Research in mathematics Education, 32(2), 124-158. https://doi.org/10.2307/749671

Guimarães, G. (2002). Interpretando e construindo gráficos de barras. [Doctoral dissertation, Universidad Federal de Pernambuco, Brasil]

MECD. (2014). Real Decreto 126/2014, de 28 de febrero, por el que se establece el currículo básico de la Educación Primaria. Author. 
MEP. (2012). Programa de estudio matemáticas, I, II y III ciclos de la educación general básica y ciclo diversificado. San José: Author.

MINEDUC. (2012). Matemática educación básica. Bases curriculares. Unidad de Currículum y Evaluación.

Pagan, A., Leite, A. P., Magina, S., \& Cazorla, I. (2008). A leitura e interpretação de gráficos e tabelas no Ensino Fundamental e Médio. In V. Gitirana, F. Bellemain, \& V. Andrade (Eds.), Anais do $2^{o}$ Simpósio Internacional de Pesquisa em Educação Matemática (pp. 1-10). Universidad Federal de Pernambuco. https://dx.doi.org/10.24109/2176-6681.rbep.92i232.675

Ridgway, J. (2016). Implications of the data revolution for statistics education. International Statistical Review, 84(3), 528-549. https://doi.org/10.1111/insr.12110

Shaughnessy, J. M., Garfield, J., \& Greer, B. (1996). Data handling. In A. J. Bishop, K. Clements, C. Keitel, J. Kilpatrick, \& C. Laborde (Eds.), International handbook of mathematics education (pp. 205-237). Kluwer Academic Publishers. https://doi.org/10.1007/978-94-009-1465-0

Shah, P., \& Hoeffner, J. (2002). Review of graph comprehension research: implications for instruction. Educational Psychology Review, 14(1), 47-69.

Tufte, E. R. (2001). The visual display of quantitative information. Graphics Press.

PEDRO ARTEAGA CEZÓN

Facultad de Ciencias de la Educación, Campus de Cartuja Universidad de Granada 